\title{
Influence of socioeconomic events on cause- specific mortality in urban Shanghai, China, from 1974 to 2015: a population-based longitudinal study
}

\author{
Shuo Wang MD, Xiaoyu Du PhD, Xue Han MPH, Fan Yang PhD, Jia Zhao MD, Hui Li MD, Mi Li PhD, \\ Hongwei Zhang PhD, Wenbin Liu PhD, Jiahui Song MD, Guangwen Cao MD PhD
}

Cite as: CMAJ 2018 October 1;190:E1153-61. doi: 10.1503/cmaj.180272

A related commentary will appear in a forthcoming issue.

\begin{abstract}
BACKGROUND: Understanding how socioeconomic events influence causespecific mortality is essential for optimizing disease-control strategies. We characterized long-term trends in cause-specific mortality in a stable population from a very large urban centre.
\end{abstract}

METHODS: We derived population data from 1974 to 2015 on vital status, demographics and causes of death from the death registration system in Yangpu District, Shanghai, China. We examined temporal trends in mortality and assessed the effects of age, period and birth cohort.
RESULTS: Over 41879864 person-years of follow-up, we analyzed 290332 deaths: $3.80 \%$ from communicable conditions (group 1), $86.50 \%$ from noncommunicable diseases (group 2), and 5.56\% from injuries (group 3). Age-standardized mortality decreased after 1988 for group 1 (average annual percentage change [AAPC] -6.7, 95\% confidence interval [CI] -9.3 to -4.1 ), after 1995 for group 2 (AAPC $-2.9,95 \% \mathrm{Cl}-3.5$ to -2.3$)$, and after 1994 for group 3 (AAPC $-5.4,95 \% \mathrm{Cl}-6.3$ to -4.5), after improvements in public health and clinical service infrastructure and the removal of polluting industries during the $1980 \mathrm{~s}$. We observed increased mortality from group 2 and group 3 causes in those born between 1955 and 1965 , a period that included the Great Chinese Famine. Cause-specific mortality risks increased in those born after 1949 for cancer and diabetes only.

INTERPRETATION: Birth cohorts exposed to extreme starvation in early life had increased premature cause-specific mortality in later life. Decreased causespecific mortality followed improvements in public health, medical infrastructure and pollution control, but not for cancer or diabetes, likely because of exposure to new risk factors.
A $\mathrm{n}$ understanding of the influence of socioeconomic events on cause-specific mortality is essential to the development of health policies for prevention and control of premature death. Long-term longitudinal epidemiologic data are indispensable for characterizing the influence of socioeconomic events. The Global Burden of Disease study has shown that noncommunicable chronic diseases already surpass communicable, maternal, perinatal and nutritional disorders in some developing countries, such as China. ${ }^{1-3}$ The under-5 mortality rate, a sensitive index of public health service, declined by $79 \%$ from 1996 to 2015 in China, although these rates were higher than those in high-income countries. ${ }^{4,5}$ However, the influence of socioeconomic events on cause-specific mortality has not been systemically evaluated.
Shanghai is the largest metropolis in China; it was founded as a port for international trade just after the First Opium War (1840-1842). Since the founding of the People's Republic of China in 1949, residents in Shanghai have experienced the following socioeconomic events: the development of polluting industries (beginning in 1949 and lasting until the 1980s), the Great Chinese Famine (1959-1961), the Great Proletarian Cultural Revolution (1966-1976; hereafter, the Cultural Revolution), reform and opening-up (since 1979; hereafter, economic reform), and an outbreak of hepatitis A (January 1988) (Figure 1).6,7

Residents in Shanghai were exposed to long-term pollution caused by heavy industry from 1949 until the 1980s. Living conditions were extremely poor during the Great Chinese Famine and the Cultural Revolution. The economic reform policy 


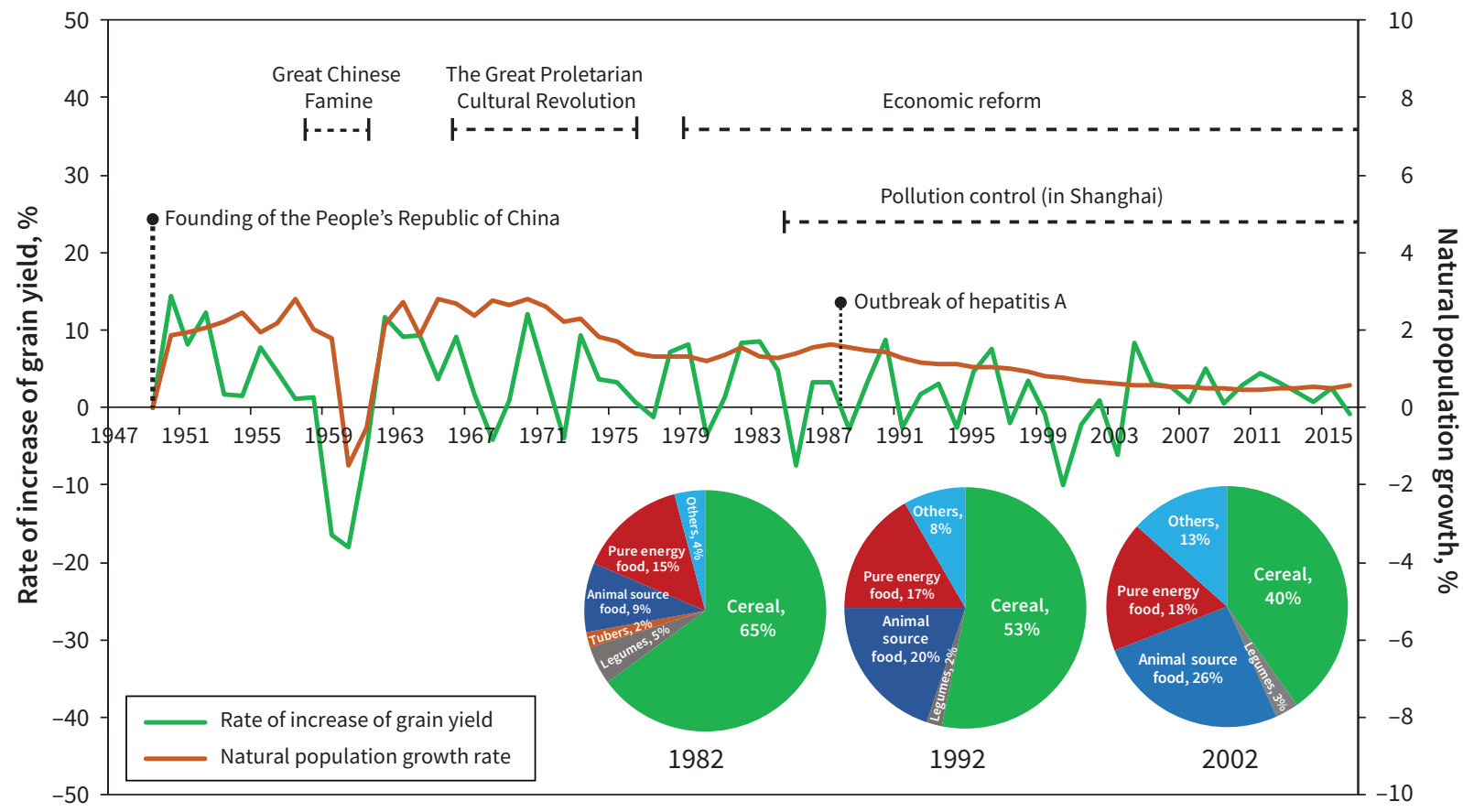

Figure 1: Rate of increase of grain yield and natural population growth rate from 1949 to 2015 in mainland China, and change in dietary patterns in urban Shanghai, China. The data on grain yield and natural population growth were derived from the National Bureau of Statistics of China. ${ }^{6}$ The information on dietary patterns in urban Shanghai was obtained from a Shanghai Center for Disease Control database. ${ }^{7}$ Pure energy food, which includes oil, starch, sugar and alcohol, provides energy but lacks protein and other nutrients.

promoted economic growth. The outbreak of hepatitis A led to improvements in the public health infrastructure. According to the World Bank standard of per capita income, Shanghai was a low-income region before 1994 and a lower-middle income region from 1996 to 2005, and became an upper-middle income region after 2006. ${ }^{8}$ The vital registration system in Shanghai was established 14 years before the Chinese national system was established in 1987.

As a result of rapid economic growth, the population has continued to increase in some districts of Shanghai over the past few decades. ${ }^{9}$ To evaluate the influence of socioeconomic events on cause-specific mortality in the naturally growing population in urban Shanghai, we selected Yangpu, an industrial district of urban Shanghai, for several reasons. First, Yangpu has a medium-sized economy among the urban districts. Second, the residents in Yangpu have experienced all the public events described above. Third, the registered population of Yangpu has been stable, ranging from $0.77 \times 10^{6}$ to $1.09 \times 10^{6}$ from 1974 to 2015. Population influx and efflux have been very limited, owing to the restriction on introduction of big businesses and the household registration system, respectively. Thus, for an investigation of the influence of socioeconomic events on the mortality of a naturally growing population, Yangpu is a good representation of urban Shanghai.

In this long-term longitudinal study, we aimed to characterize the influence of socioeconomic events on cause-specific mortality, which may assist with optimizing disease-control strategies.

\section{Methods}

\section{Sources of data}

Information on all causes of death from 1974 to 2015 was derived from the vital registration system, covering the full registered population of Yangpu, Shanghai. We mapped the 1974-2001 causes of death from the 9th International Classification of Disease (ICD) codes to aggregated 10th version (ICD-10) codes using an online database (www.icd10data.com). Since 2002, causes of death have been directly coded using ICD-10. All causes of death were classified into 3 groups according to the World Health Organization (WHO) Global Health Estimates standard classification of diseases (Table S1, Appendix 1, available at www.cmaj.ca/lookup/suppl/doi:10.1503/ cmaj.180272/-/DC1): (1) communicable, maternal, perinatal and nutritional conditions [group 1 causes], (2) chronic noncommunicable diseases [group 2 causes] and (3) injuries [group 3 causes]). ${ }^{2}$ Annual demographic data from 1974 to 2015 were obtained from the Public Security Bureau of the Yangpu administration. A quality assessment of the data is available in Appendix 2 (available at www. cmaj.ca/lookup/suppl/doi:10.1503/cmaj.180272/-/DC1).

\section{Statistical analysis}

We examined temporal trends in mortality from 1974 to 2015 by fitting joinpoint models (Version 4.3.1.0, Bethesda, MD) to the crude, logtransformed rates and age-adjusted rates, standardized according to Segi's world standard population. ${ }^{10,11}$ The trend was expressed as an average annual percentage change (AAPC). The $z$ test was employed to assess whether the AAPC was statistically different from 0 . 
We applied an age-period-cohort Poisson regression model (APC model) to evaluate the effects of age, period and birth cohort on mortality and predict the mortality trend from 2016 to 2030. ${ }^{12}$ Details on the APC model are given in Appendix 2. The joinpoint and APC models were repeated, stratified by sex.

\section{Ethics approval}

All data were deidentified. The study was approved by the ethics committee of the Centre for Disease Control and Prevention of Yangpu District, Shanghai, China.

\section{Results}

We analyzed all registered permanent residents in Yangpu, with a total of 41879864 person-years. A total of 290332 deaths (154050 men and 136282 women) occurred between 1974 and 2015. Group 1 causes, group 2 causes and group 3 causes accounted for $3.80 \%$, $86.50 \%$ and $5.56 \%$ of all-cause mortality, respectively. The top 5 leading causes of death for men were cardio-cerebrovascular disease (stroke, ischemic heart disease and hypertensive heart disease); cancer; respiratory disease, including chronic obstructive pulmonary disease (COPD) and asthma; injuries; and digestive disease, including liver cirrhosis and peptic ulcer disease (Table S2, Appendix 1). The top 5 leading causes of death for women were cardio-cerebrovascular disease, cancer, respiratory disease, injuries and diabetes (Table S2, Appendix 1). In the working population younger than 60 years, cancer, cardio-cerebrovascular disease, injury, infectious and parasitic disease, and digestive disease were the top 5 leading causes of death for men (Table 1). Cancer, cardio-cerebrovascular diseases, injuries, infectious and parasitic diseases, and congenital anomalies were the top 5 leading causes of death for women (Table 1). Cancer was the leading cause of death among women aged 30 to 59 and men aged 30 to 74 years, whereas cardio-cerebrovascular disease was the leading cause of death among women older than 59 and men older than 75 years.

\section{Mortality trends}

From 1974 to 2015, the proportion of deaths resulting from group 1 and 3 causes continually decreased, whereas the proportion of deaths from group 2 causes continually increased (Figure 2). Table 2 shows the trends and breakpoints of age-standardized, cause-specific mortality from 1974 to 2015 . The age-standardized mortality of the major causes decreased over the past 42 years, but that of diabetes increased at an annual average rate of $1.7 \%$. For group 1 causes, mortality decreased rapidly (AAPC $-6.7,95 \%$ confidence interval $[\mathrm{CI}]-9.3$ to -4.1 ) from 1988 to 2015 , when the large outbreak of hepatitis A was controlled. For group 2 causes, age-standardized mortality decreased (AAPC $-2.9,95 \% \mathrm{Cl}-3.5$ to -2.3 ) from 1995 to 2015). Of those, deaths from cancer began to decrease from 1991, almost 8 to 10 years after polluting industries were removed. From 1974, increasing mortality trends were seen for neurologic conditions (AAPC 5.4, 95\% Cl 4.1 to 6.6), congenital anomalies (AAPC $4.2,95 \% \mathrm{Cl} 1.1$ to 7.5 ), diabetes mellitus (AAPC 3.2, 95\% Cl 2.5 to 3.9) and cardio-cerebrovascular disease (AAPC $0.8,95 \% \mathrm{Cl} 0.3$ to 1.2 ), but the mortality trends for all group 2 causes began to decrease between 1990 (for digestive diseases) and 2005 (for diabetes mellitus). For group 3 causes, we observed an evident decrease (AAPC $-5.4,95 \% \mathrm{Cl}-6.3$ to -4.5 ) after the breakpoint in
1994. The mortality trends for group 1 and 2 causes were similar in both genders. We observed decreasing mortality trends for group 3 causes, but the breakpoints were different in men and women (Table S3, Appendix 1). Decreases in mortality from group 2 and 3 causes followed clinical service improvements that began in the late $1980 \mathrm{~s}$.

\section{Age, period and cohort effects on leading causes of mortality}

Using the APC model, we analyzed the effects of age, birth cohort and period on mortality. Deaths from cardio-cerebrovascular disease, cancer and diabetes greatly decreased from 1990 , especially after 2000 , in the age groups from 60 to 70 years; that of respiratory disease decreased in almost all age groups (Figure 3A1, 3B1, 3C1 and 3D1). Birth cohort analysis indicated that all-cause mortality; deaths from group 2 causes including cardio-cerebrovascular disease, cancer, diabetes and digestive disease; and deaths from injuries increased in the population born between 1955 and 1965 (Figure 3A2, 3B2 and 3C2 and Figures S1 and S2 in Appendix 1), covering the period of the Great Chinese Famine (1959-1961). From the fitting trend of the birth cohort in the APC model, we found that the risks of death from cardiocerebrovascular disease, cancer, diabetes and respiratory disease peaked in the populations born in 1921, 1928, 1928 and 1911, and then declined, respectively. However, the risks of death from cancer and diabetes increased in those born after 1949 (Figure 3A3, 3B3, 3C3 and 3D3). Trends for the leading causes of death in the birth cohort were similar in both genders, except for diabetes mellitus. The risks of diabetes mellitus in the birth cohorts kept increasing after 1940 in men, but decreased in women (Figures S3 and S4, Appendix 1).

\section{Projecting causes of death in 2026-2030}

Older adults (aged 65 years and older) accounted for $4.59 \%$ of the total population in 1974; this proportion increased to $19.15 \%$ in 2015. The number of older adults is expected to peak during 20212025 , accounting for $33.15 \%$, after which it will decrease. Figure 4 shows the proportionate distribution of cause-specific mortality by sex in the periods 1976-1980, 2011-2015 and 2026-2030. It is projected that a total of 11354 women and 20996 men will die between 2026 and 2030. The proportionate distribution of group 1 and 3 causes will keep decreasing (the proportion of group 1 causes: $6.67 \%$ in $1976-1980,2.43 \%$ in $2011-2015$, and $2.31 \%$ in $2026-2030$; that of injuries: $7.83 \%$ in $1976-1980,3.71 \%$ in $2011-2015$, and $3.08 \%$ in 2026-2030). Cardio-cerebrovascular disease and cancer will remain the top 2 killers. Further, their proportionate distributions will continue to increase in both sexes. It appears that diabetes will become the third most common cause of death as an indirect consequence of the proportion of deaths from respiratory diseases continuing to decrease over time. However, diabetes will likely remain the fourth most common cause of death in men in 2026-2030.

\section{Interpretation}

This study had 4 main findings. First, age-standardized mortality from group 1, 2 and 3 causes decreased rapidly after 1988, 1995 and 1994, respectively. Second, cardio-cerebrovascular disease-, cancer-, and diabetes-related deaths clearly increased in those born around the time of the Great Chinese Famine. Third, the risks of the major 
Table 1: Cause of death, by age group, 1974-2015

Causes of death

\section{Women}

Cardio-cerebrovascular diseases

Cancer

Respiratory diseases

Injuries

Diabetes mellitus

Digestive diseases

Neurological conditions

Infectious and parasitic diseases

Genitourinary diseases

Respiratory infections

Musculoskeletal diseases

Mental and substance use disorders

Congenital anomalies

Neonatal conditions

Endocrine, blood, immune disorders

Skin diseases

Maternal conditions

Nutritional deficiencies

Sense organ diseases

Oral conditions

Unknown

\section{Men}

Cardio-cerebrovascular disease

Cancer

Respiratory diseases

Injuries

Digestive diseases

Infectious and parasitic diseases

Diabetes mellitus

Neurological conditions

Genitourinary diseases

Respiratory infections

Mental and substance use disorders

Neonatal conditions

Congenital anomalies

Musculoskeletal diseases

Endocrine, blood, immune disorders

Skin diseases

Sense organ diseases

Nutritional deficiencies

Oral conditions

Maternal conditions

Unknown

\section{Age $<30 \mathrm{yr}$ \\ $n(\%)$}

$n=3536$

$162(4.58)$

524 (14.82)

$35(0.99)$

$852(24.1)$

$25(0.71)$

64 (1.81)

$91(2.57)$

164 (4.64)

63 (1.78)

149 (4.21)

92 (2.6)

84 (2.38)

515 (14.56)

567 (16.04)

37 (1.05)

4 (0.11)

38 (1.07)

$5(0.14)$

$0(0)$

0 (0)

65 (1.84)

$n=4731$

246 (5.2)

672 (14.2)

67 (1.42)

1267 (26.78)

107 (2.26)

$238(5.03)$

$18(0.38)$

157 (3.32)

$111(2.35)$

206 (4.35)

$108(2.28)$

746 (15.77)

593 (12.53)

$27(0.57)$

58 (1.23)

$4(0.08)$

$1(0.02)$

$3(0.06)$

$0(0)$

$0(0)$

102 (2.16)
Age 30-44

$n=3627$

467 (12.88)

1552 (42.79)

92 (2.54)

600 (16.54)

58 (1.6)

83 (2.29)

$88(2.43)$

185 (5.1)

89 (2.45)

$15(0.41)$

123 (3.39)

$127(3.5)$

58 (1.6)

0 (0)

38 (1.05)

$6(0.17)$

$16(0.44)$

$1(0.03)$

1 (0.03)

$0(0)$

$28(0.77)$

$n=6237$

845 (13.55)

2140 (34.31)

174 (2.79)

$1257(20.15)$

280 (4.49)

$640(10.26)$

81 (1.3)

$147(2.36)$

138 (2.21)

$29(0.46)$

267 (4.28)

$0(0)$

$45(0.72)$

$24(0.38)$

$34(0.55)$

$9(0.14)$

$0(0)$

$0(0)$

$0(0)$

$0(0)$

$127(2.04)$
Age 45-59 yr

$n(\%)$

$n=12787$

3249 (25.41)

6134 (47.97)

486 (3.8)

729 (5.7)

$304(2.38)$

393 (3.07)

$148(1.16)$

$530(4.14)$

254 (1.99)

$51(0.4)$

155 (1.21)

$155(1.21)$

$56(0.44)$

0 (0)

70 (0.55)

$12(0.09)$

0 (0)

$1(0.01)$

$0(0)$

$0(0)$

$60(0.47)$

$n=22056$

5445 (24.69)

10274 (46.58)

887 (4.02)

$1491(6.76)$

818 (3.71)

$1382(6.27)$

400 (1.81)

$246(1.12)$

$266(1.21)$

$116(0.53)$

$278(1.26)$

0 (0)

$34(0.15)$

$72(0.33)$

$69(0.31)$

$6(0.03)$

$1(0)$

$0(0)$

$0(0)$

$0(0)$

271 (1.23)
Age 60-74 yr

$n(\%)$

$n=37179$

14046 (37.78)

12037 (32.38)

3307 (8.89)

1409 (3.79)

1961 (5.27)

1301 (3.5)

589 (1.58)

787 (2.12)

489 (1.32)

$199(0.54)$

$259(0.7)$

$200(0.54)$

32 (0.09)

0 (0)

$136(0.37)$

66 (0.18)

$0(0)$

2 (0.01)

$3(0.01)$

$1(0)$

$355(0.95)$

$n=53722$

18119 (33.73)

21303 (39.65)

6184 (11.51)

$1581(2.94)$

1354 (2.52)

1305 (2.43)

$1449(2.7)$

655 (1.22)

526 (0.98)

$302(0.56)$

$181(0.34)$

$0(0)$

$42(0.08)$

$148(0.28)$

87 (0.16)

$38(0.07)$

$2(0)$

$1(0)$

$1(0)$

$0(0)$

$444(0.83)$

Age $>75 \mathrm{yr}$

$n(\%)$

All ages

$n$ (\%)

$n=79153$

$n=136282$

33468 (42.28)

$51392(37.71)$

12170 (15.38)

32417 (23.79)

9469 (11.96)

13389 (9.82)

4524 (5.72)

8114 (5.95)

3528 (4.46)

5876 (4.31)

2973 (3.76)

4814 (3.53)

1848 (2.33)

2764 (2.03)

$573(0.72)$

2239 (1.64)

759 (0.96)

1654 (1.21)

1063 (1.34)

1477 (1.08)

399 (0.5)

1028 (0.75)

$181(0.23)$

$747(0.55)$

$697(0.51)$

$567(0.42)$

$505(0.37)$

$289(0.21)$

$54(0.04)$

15 (0.01)

$6(0.01)$

$10(0.01)$

$2(0)$

$3(0)$

7723 (9.76)

8230 (6.04)

$n=67304$

$n=154050$

25718 (38.21)

$50373(32.70)$

15540 (23.09)

49929 (32.41)

12249 (18.2)

19561 (12.70)

2420 (3.6)

8016 (5.20)

$1986(2.95)$

4545 (2.95) 


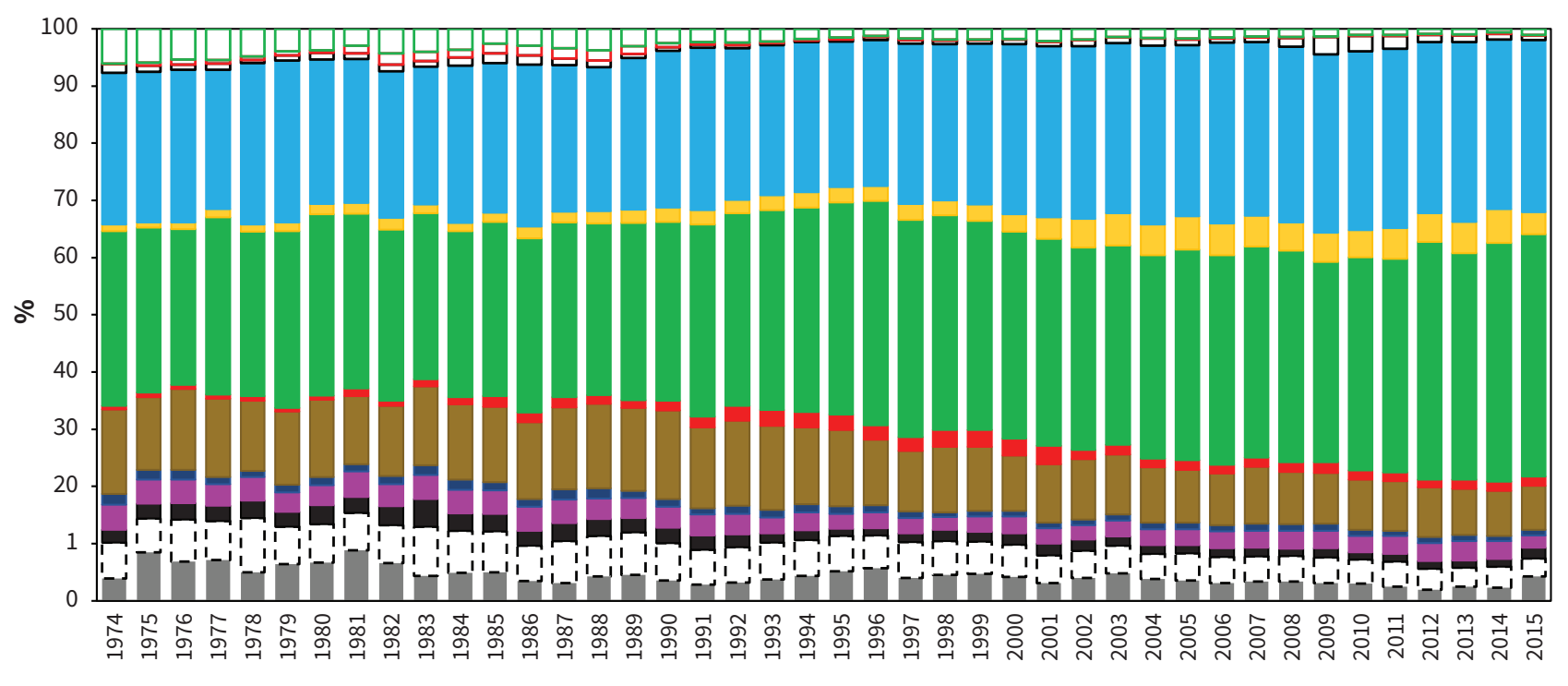

Figure 2: Proportions of causes of death in Yangpu District, Shanghai, China, 1974-2015. Solid lines and empty bars represent group 1 causes (communicable, maternal, perinatal and nutritional conditions); coloured solid bars indicate group 2 causes (chronic noncommunicable diseases); dotted lines and empty bars indicate group 3 causes (injuries).

group 2 cause-related deaths peaked in those born between 1911 and 1928, and then declined, but the risks of death from cancer and diabetes began to increase in those born after 1949. Fourth, cardiocerebrovascular disease and cancer remain the top 2 killers. Diabetes will likely be the third most common cause of death in women and the fourth most common cause of death in men.

The trends in age-standardized mortality reflect the effect of public health efforts and the nature of life-threatening diseases. Deaths from group 1 causes decreased after 1988, corresponding to the actions taken by the municipal government to greatly enhance public health infrastructure to control infectious disease, after the outbreak of hepatitis A in January $1988 .{ }^{13}$ These findings are consistent with data from the Global Burden of Disease study, which showed that after 1990, standardized mortality rates from group 1 and group 3 causes were lower in Shanghai than in mainland China or the rest of the world (Table S4, Appendix 1). ${ }^{14}$ We speculate that these reductions in mortality are attributable to improvements in medical services in Shanghai. Shanghai had established a sound disease prevention and control network including 19 centres for disease control and 240 community health centres after the outbreak of hepatitis A in 1988. Similarly, improvements in air quality and medical services from the 1980 s onward may account for the reduction in deaths from respiratory diseases such as COPD, as smoking and air pollution are well-established risk factors for COPD. ${ }^{15}$
However, it is difficult to reduce the burden of group 2 causes. Age-standardized mortality from cancer started to decrease from 1991, possibly because polluting industries were removed from urban Shanghai after the 1980s. Deaths from cardio-cerebrovascular disease and diabetes began to decrease after 1998 and 2005, possibly owing to improvements in medical service after the 1980s and in health education, especially the World Bank-supported mass health promotion program that was begun in 1996, all of which played active roles. In keeping with these findings, after 2013, standardized mortality rates from group 2 causes were also lower in Shanghai than in the rest of the world, including mainland China, except for diabetes and digestive diseases (Table S4, Appendix 1). ${ }^{14}$

The risks of death by cardio-cerebrovascular disease, cancer and diabetes peaked in those born between 1920 and 1930, which may be related to the poor condition of the health care system between 1960 and 1980. The medical system was overburdened during the Great Chinese Famine (1959-1961) and the Cultural Revolution (1966-1976). Previous studies have shown that exposure to the Great Chinese Famine in early life increased the risks of obesity, hyperglycemia, type 2 diabetes, hypertension and fatty liver disease in adulthood, and also increased the risk of schizophrenia and death from stomach cancer in later life. ${ }^{16-22}$ Our findings further suggested that exposure to the famine at the perinatal stage increased deaths from cardio-cerebrovascular disease (including 
stroke), cancer, diabetes, digestive disease and injury. Metabolic syndrome is an important risk factor of stroke, particularly among women and those with ischemic stroke. ${ }^{23}$ The associations between exposure to the famine and metabolic syndrome may be partially explained by insulin resistance. Exposure to extreme starvation leads to poor development of pancreatic $\beta$-cell mass and function, which may persist in later life. ${ }^{24}$ Exposure to adverse social environments in early life increases the risk of chronic diseases in later life.
In addition, people born around the time of the famine might have a compensatory mental orientation toward overconsumption.

The risks of death from chronic diseases in those born after 1940 declined, but the risks of death from cancer and diabetes increased in those born after 1949 (Figure 3B3 and 3C3), indicating that the exposure of their risk factors kept increasing. High intake of red and processed meat, tobacco smoking, overweight or obesity, physical inactivity, low intake of vegetables, and alcohol consumption

Table 2: Trends in age-standardized mortality rates: 1974-2015

\begin{tabular}{|c|c|c|c|c|c|c|c|c|}
\hline \multirow[b]{2}{*}{ Disease } & \multirow[b]{2}{*}{$\begin{array}{c}\text { AAPC } \\
(95 \% \mathrm{Cl}) \\
(1974-2015)\end{array}$} & \multicolumn{2}{|c|}{ Joinpoint trend 1} & \multicolumn{2}{|c|}{ Joinpoint trend 2} & \multicolumn{2}{|c|}{ Joinpoint trend 3} & \multirow[b]{2}{*}{$\begin{array}{c}\text { AAPC } \\
(95 \% \mathrm{Cl}) \\
\text { (1st breakpoint } \\
\text { to } 2015)^{\star}\end{array}$} \\
\hline & & Years & $\begin{array}{c}\text { AAPC } \\
(95 \% \mathrm{CI})\end{array}$ & Years & $\begin{array}{c}\text { AAPC } \\
(95 \% \mathrm{CI})\end{array}$ & Years & $\begin{array}{c}\text { AAPC } \\
(95 \% \mathrm{Cl})\end{array}$ & \\
\hline $\begin{array}{l}\text { Communicable, } \\
\text { maternal, perinatal and } \\
\text { nutritional conditions }\end{array}$ & $\begin{array}{c}-3.5 \\
(-5.2 \text { to } 1.8) \dagger\end{array}$ & 1974-1988 & $\begin{array}{c}1.6 \\
(0.2 \text { to } 3.1) \dagger\end{array}$ & 1988-1992 & $\begin{array}{c}-22.2 \\
(-34.0 \text { to }-8.2) \dagger\end{array}$ & $1992-2015$ & $\begin{array}{c}-3.0 \\
(-4.2 \text { to }-1.7) \dagger\end{array}$ & $\begin{array}{c}-6.7 \\
(-9.3 \text { to }-4.1) \dagger\end{array}$ \\
\hline $\begin{array}{l}\text { Infectious and parasitic } \\
\text { diseases }\end{array}$ & $\begin{array}{c}-5.0 \\
(-6.7 \text { to }-3.3) \dagger\end{array}$ & 1974-1989 & $\begin{array}{c}-3.7 \\
(-5.1 \text { to }-2.2) \dagger\end{array}$ & 1989-1994 & $\begin{array}{c}-9.1 \\
(-20.1 \text { to } 3.5)\end{array}$ & 1994-2015 & $\begin{array}{c}-5.0 \\
(-6.3 \text { to }-3.6) \dagger\end{array}$ & $\begin{array}{c}-6.5 \\
(-9.6 \text { to }-3.4) \dagger\end{array}$ \\
\hline Maternal conditions & - & - & - & - & - & - & - & - \\
\hline Neonatal conditions & $\begin{array}{c}-1.9 \\
(-6.4 \text { to } 2.8)\end{array}$ & 1974-1988 & $\begin{array}{c}6.8 \\
\text { (3.3 to } 10.6) \dagger\end{array}$ & $1988-1991$ & $\begin{array}{c}-40.8 \\
(-68.0 \text { to } 9.5)\end{array}$ & 1991-2015 & $\begin{array}{c}-0.6 \\
(-3.0 \text { to } 1.9)\end{array}$ & $\begin{array}{c}-8.7 \\
(-22.1 \text { to } 7.0)\end{array}$ \\
\hline Respiratory infections & $\begin{array}{c}-1.2 \\
(-5.3 \text { to } 3.1)\end{array}$ & 1974-1987 & $\begin{array}{c}3.8 \\
(-1.8 \text { to } 9.8)\end{array}$ & 1987-1993 & $\begin{array}{c}-21.4 \\
(-39.0 \text { to } 1.2)\end{array}$ & 1993-2015 & $\begin{array}{c}2.2 \\
(-0.8 \text { to } 5.2)\end{array}$ & $\begin{array}{c}-6.1 \\
(-12.8 \text { to } 0.4)\end{array}$ \\
\hline $\begin{array}{l}\text { Chronic } \\
\text { noncommunicable } \\
\text { diseases }\end{array}$ & $\begin{array}{c}-1.3 \\
(-1.6 \text { to }-0.9) \dagger\end{array}$ & 1974-1995 & $\begin{array}{c}0.3 \\
(0.0 \text { to } 0.7) \dagger\end{array}$ & 1995-2004 & $\begin{array}{c}-4.7 \\
(-5.9 \text { to }-3.5) \dagger\end{array}$ & 2004-2015 & $\begin{array}{c}-1.5 \\
(-2.2 \text { to }-0.7) \dagger\end{array}$ & $\begin{array}{c}-2.9 \\
(-3.5 \text { to }-2.3) \dagger\end{array}$ \\
\hline Cancer & $\begin{array}{c}-0.7 \\
(-0.9 \text { to }-0.5) \dagger\end{array}$ & 1974-1991 & $\begin{array}{c}0.4 \\
(-0.0 \text { to } 0.9)\end{array}$ & 1991-2015 & $\begin{array}{c}-1.5 \\
(-1.7 \text { to }-1.3) \dagger\end{array}$ & & & $\begin{array}{c}-1.5 \\
(-1.7 \text { to }-1.3) \dagger\end{array}$ \\
\hline $\begin{array}{l}\text { Cardio-cerebrovascular } \\
\text { disease }\end{array}$ & $\begin{array}{c}-1.0 \\
(-1.7 \text { to }-0.2) \dagger\end{array}$ & 1974-1998 & $\begin{array}{c}0.8 \\
(0.3 \text { to } 1.2) \dagger\end{array}$ & $1998-2003$ & $\begin{array}{c}-9.2 \\
(-14.1 \text { to }-4.1) \dagger\end{array}$ & 2003-2015 & $\begin{array}{c}-0.8 \\
(-1.8 \text { to } 0.2)\end{array}$ & $\begin{array}{c}-3.3 \\
(-4.4 \text { to }-2.2) \dagger\end{array}$ \\
\hline Congenital anomalies & $\begin{array}{c}-1.5 \\
(-4.2 \text { to } 1.3)\end{array}$ & 1974-1988 & $\begin{array}{c}4.2 \\
(1.1 \text { to } 7.5) \dagger\end{array}$ & $1988-1993$ & $\begin{array}{c}-18.4 \\
(-32.9 \text { to }-0.8) \dagger\end{array}$ & 1993-2015 & $\begin{array}{c}-0.8 \\
(-3.2 \text { to } 1.6)\end{array}$ & $\begin{array}{c}-5.5 \\
(-9.1 \text { to }-1.7) \dagger\end{array}$ \\
\hline Diabetes mellitus & $\begin{array}{c}1.7 \\
(0.9 \text { to } 2.4) \dagger\end{array}$ & 1974-2005 & $\begin{array}{c}3.2 \\
(2.5 \text { to } 3.9) \dagger\end{array}$ & 2005-2015 & $\begin{array}{c}-2.9 \\
(-5.1 \text { to }-0.7) \dagger\end{array}$ & & & $\begin{array}{c}-2.9 \\
(-5.1 \text { to }-0.7) \dagger\end{array}$ \\
\hline Digestive diseases & $\begin{array}{c}-2.7 \\
(-3.6 \text { to }-1.8) \dagger\end{array}$ & 1974-1990 & $\begin{array}{c}-0.4 \\
(-1.5 \text { to } 0.7)\end{array}$ & $1990-1998$ & $\begin{array}{c}-7.6 \\
(-11.0 \text { to }-4.1) \dagger\end{array}$ & $1998-2015$ & $\begin{array}{c}-2.5 \\
(-3.4 \text { to }-1.5) \dagger\end{array}$ & $\begin{array}{c}-4.7 \\
(-6.8 \text { to }-2.6) \dagger\end{array}$ \\
\hline $\begin{array}{l}\text { Endocrine, blood, } \\
\text { immune disorders }\end{array}$ & $\begin{array}{c}-0.5 \\
(-5.6 \text { to } 4.9)\end{array}$ & 1974-2001 & $\begin{array}{c}0.5 \\
\text { (-1.1 to } 2.2)\end{array}$ & 2001-2005 & $\begin{array}{c}-17.2 \\
(-50.6 \text { to } 38.7)\end{array}$ & 2005-2015 & $\begin{array}{c}4.1 \\
(-3.1 \text { to } 11.9)\end{array}$ & $\begin{array}{c}-3.6 \\
(-15.9 \text { to } 10.4)\end{array}$ \\
\hline Genitourinary diseases & $\begin{array}{c}-2.7 \\
(-5.1 \text { to }-0.3) \dagger\end{array}$ & 1974-1995 & $\begin{array}{c}-0.5 \\
(-1.4 \text { to } 0.4)\end{array}$ & $1995-1998$ & $\begin{array}{c}-15.6 \\
(-39.5 \text { to } 18.0)\end{array}$ & $1998-2015$ & $\begin{array}{c}-2.9 \\
(-4.2 \text { to }-1.6) \dagger\end{array}$ & $\begin{array}{c}-5.4 \\
(-7.2 \text { to }-3.5) \dagger\end{array}$ \\
\hline $\begin{array}{l}\text { Mental and substance } \\
\text { use disorders }\end{array}$ & $\begin{array}{c}-0.6 \\
(-3.4 \text { to } 2.3)\end{array}$ & 1974-2002 & $\begin{array}{c}-1.2 \\
(-2.1 \text { to }-0.3) \dagger\end{array}$ & $2002-2013$ & $\begin{array}{c}-4.2 \\
(-8.9 \text { to } 0.6)\end{array}$ & $2013-2015$ & $\begin{array}{c}33.7 \\
(-21.7 \text { to } 128.2)\end{array}$ & $\begin{array}{c}0.5 \\
(-5.6 \text { to } 7.1)\end{array}$ \\
\hline Musculoskeletal diseases & $\begin{array}{c}-3.5 \\
(-4.1 \text { to }-2.8) \dagger\end{array}$ & 1974-2015 & $\begin{array}{c}-3.5 \\
(-4.1 \text { to }-2.8) \dagger\end{array}$ & & & & & - \\
\hline Neurological conditions & $\begin{array}{c}0.1 \\
(-1.8 \text { to } 2.1)\end{array}$ & 1974-1999 & $\begin{array}{c}5.4 \\
(4.1 \text { to } 6.6) \dagger\end{array}$ & 1999-2004 & $\begin{array}{c}-21.0 \\
(-30.8 \text { to }-9.7) \dagger\end{array}$ & 2004-2015 & $\begin{array}{c}-0.7 \\
(-4.0 \text { to } 2.7)\end{array}$ & $\begin{array}{c}-7,1 \\
(-10.0 \text { to }-4.1) \dagger\end{array}$ \\
\hline Oral conditions & - & - & - & - & - & - & - & - \\
\hline Respiratory diseases & $\begin{array}{c}-3.5 \\
(-4.2 \text { to }-2.7) \dagger\end{array}$ & 1974-1993 & $\begin{array}{c}0.4 \\
(-0.4 \text { to } 1.2)\end{array}$ & 1993-2005 & $\begin{array}{c}-8.4 \\
(-10.0 \text { to }-6.8) \dagger\end{array}$ & & & $\begin{array}{c}-8.4 \\
(-10.0 \text { to }-6.8) \dagger\end{array}$ \\
\hline Sense organ diseases & - & - & - & - & - & - & - & - \\
\hline Skin diseases & - & - & - & - & - & - & - & - \\
\hline Injuries & $\begin{array}{c}-3.1 \\
(-3.7 \text { to }-2.4) \dagger\end{array}$ & 1974-1994 & $\begin{array}{c}-0.6 \\
(-1.5 \text { to } 0.3)\end{array}$ & 1994-2015 & $\begin{array}{c}-5.4 \\
(-6.3 \text { to }-4.5) \dagger\end{array}$ & & & $\begin{array}{c}-5.4 \\
(-6.3 \text { to }-4.5) \dagger\end{array}$ \\
\hline
\end{tabular}

Note: $\mathrm{AAPC}=$ average annual percentage change, $\mathrm{Cl}=$ confidence interval, $-=$ the number is too small to calculate AAPC values ${ }^{*} 1$ st breakpoint corresponds to the last year of joinpoint trend 1 and the first year of joinpoint trend 2 .

†AAPC value is significantly different from 0 at $\alpha=0.05$. 
A1

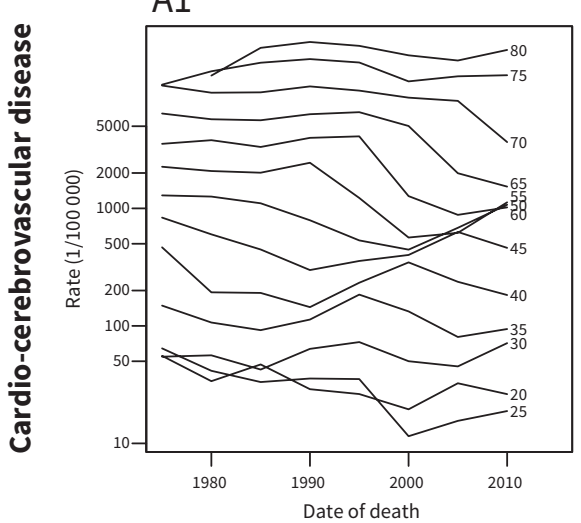

B1

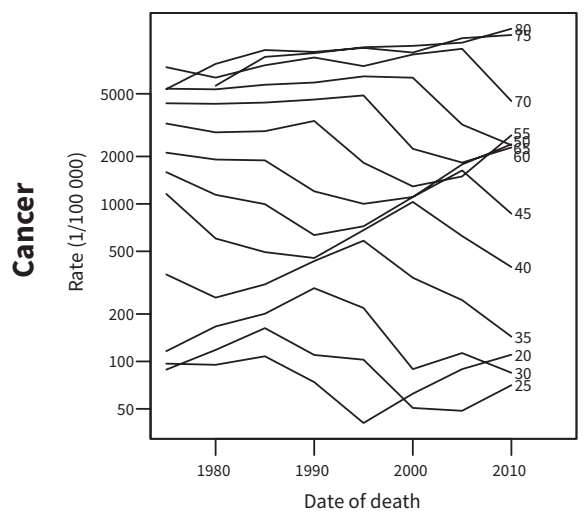

C1

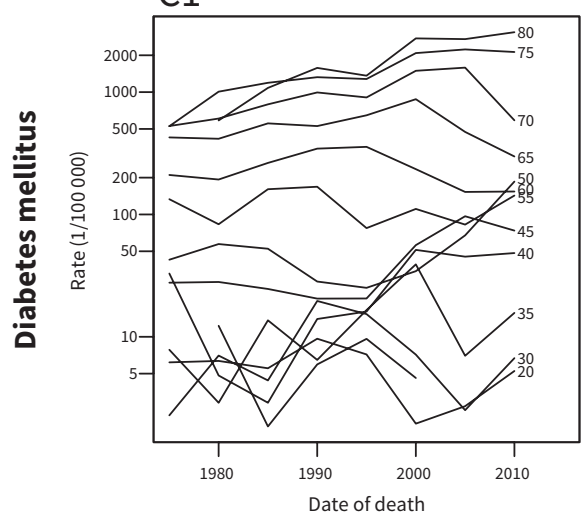

D1

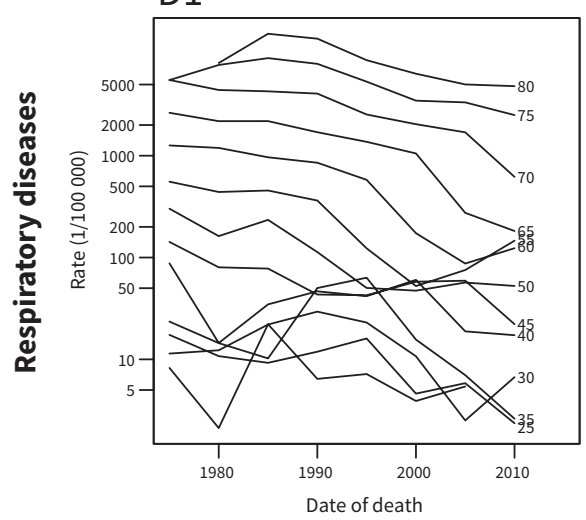

A2

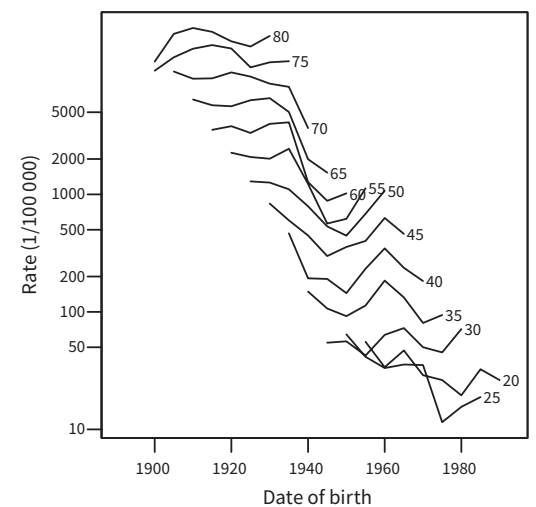

B2

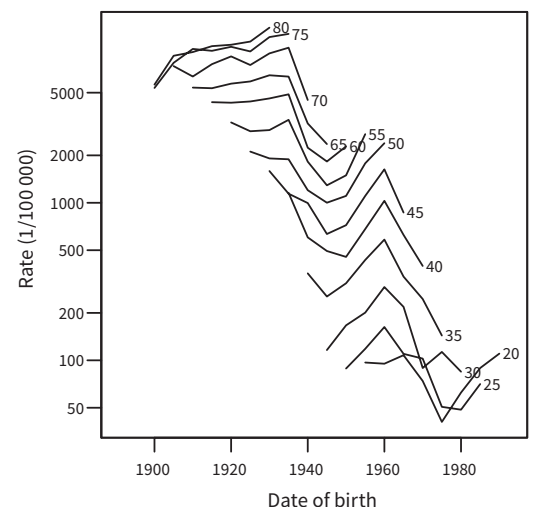

C2

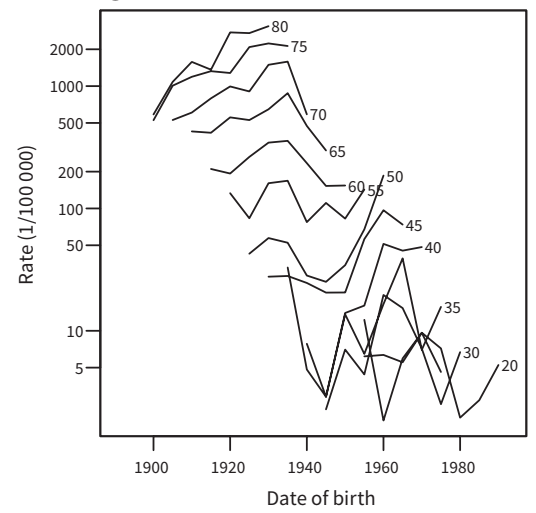

D2

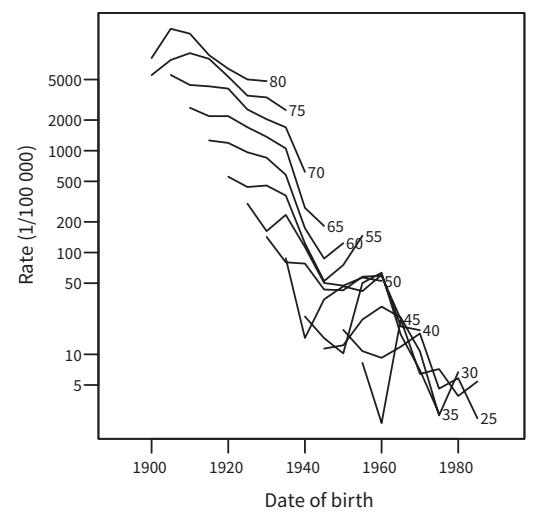

A3

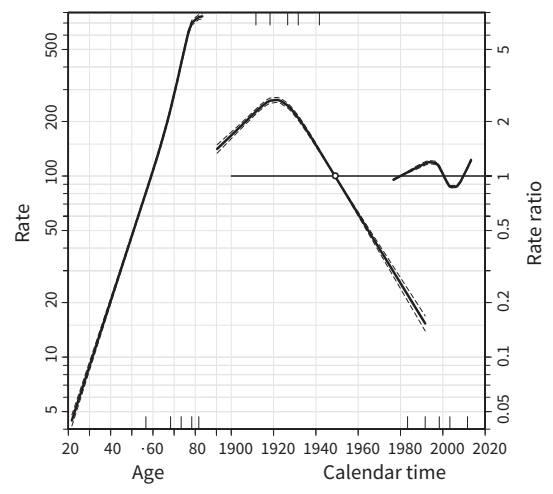

B3

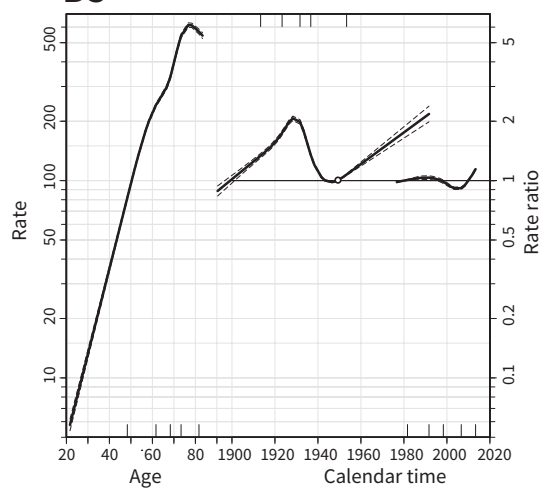

C3

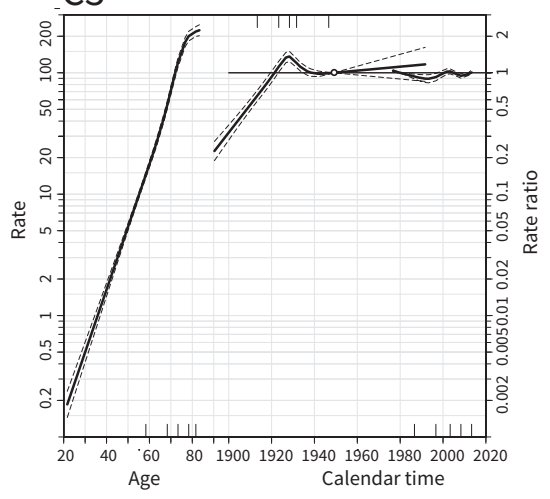

D3

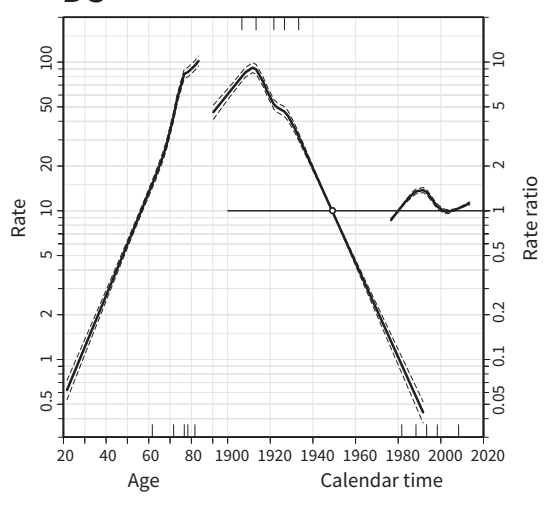

Figure 3: Age-specific mortality rates (per 100000) by period and birth cohort and age, period, and cohort effects for the mortality rates of major chronic diseases in Yangpu, Shanghai, China (1974-2015). Each row of plots, from left to right, are age-specific mortality rates by period, age-specific mortality by birth cohort, and an age-period-cohort Poisson (APC) regression plot. The APC regression plot has 3 curves depicting, from left to right, trends in mortality rate by age (yr) for the reference birth cohort (1949), the risk ratio of the cohort effect compared with the reference birth cohort (1949), and the risk ratio of the calendar period effect compared with the reference cohort (1980). Dotted lines show the $95 \%$ confidence intervals of the 3 components (solid lines). 


\section{A: Women}

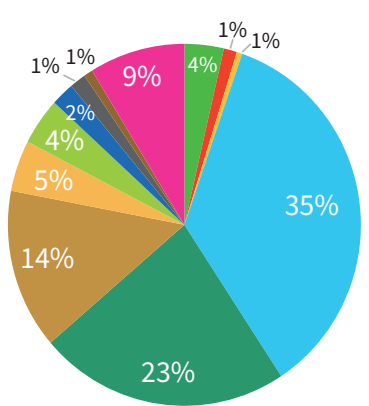

$1976-1980$

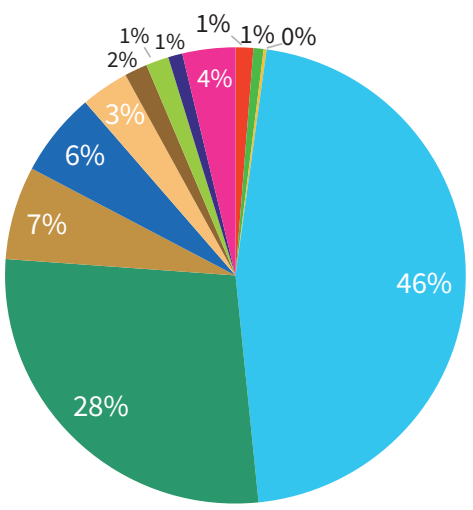

2011-2015

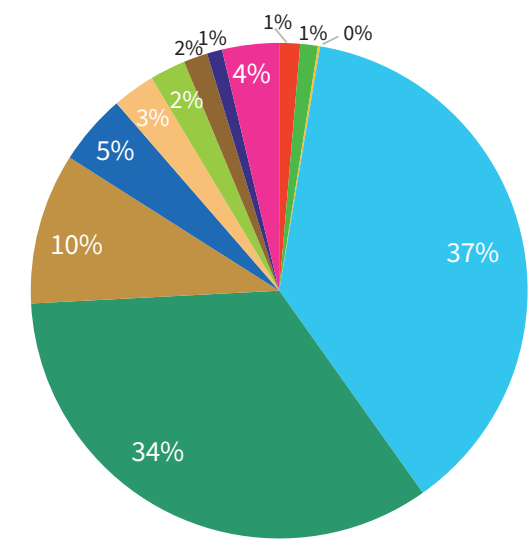

2011-2015

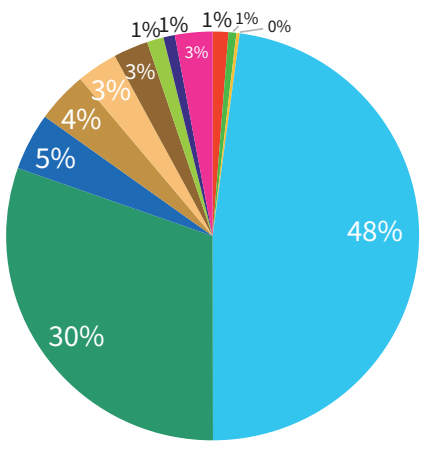

$2026-2030$

\section{B: Men}

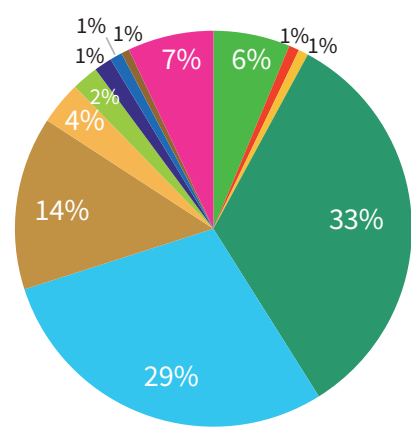

$1976-1980$

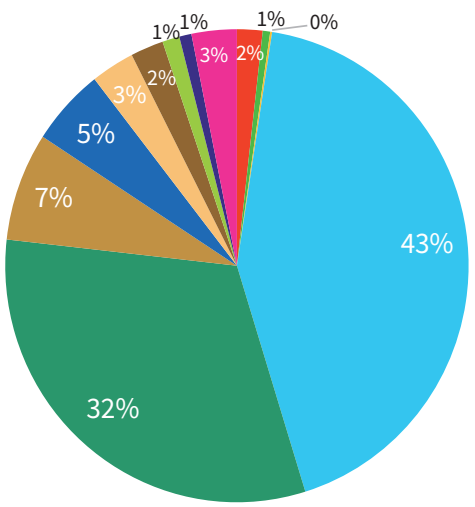

2026-2030

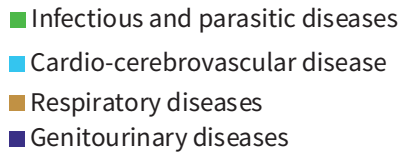

- Infectious and parasitic diseases

- Cardio-cerebrovascular disease

- Respiratory diseases

- Genitourinary diseases

$$
\begin{aligned}
& \text { Respiratory infections } \\
& \text { Cancer } \\
& \text { Digestive diseases } \\
& \text { Neurological conditions }
\end{aligned}
$$

Maternal, perinatal and nutritional conditions - Diabetes mellitus

Other chronic noncommunicable diseases

- Injuries

Figure 4: Pie charts of all causes of death in women and men from 1976 to 1980 and from 2011 to 2015, and predicted from 2026 to 2030 , scaled to the number of deaths during each period, (A) for women; (B) for men.

increase the risk of cancer. ${ }^{25,26}$ According to a dietary survey in urban Shanghai, the proportion of intake of red meat increased from $9 \%$ in 1982 to $26 \%$ in 2002, whereas the rate of cereal intake declined from $65 \%$ to $40 \%$ (Figure 1 ). ${ }^{7}$ Tobacco smoking has increased substantially since the 1980 s. More than $50 \%$ of Chinese men were smokers in 2010, with a high uptake rate in men before the age of 20 years. ${ }^{27,28}$ Diabetes shares the same risk factors as some cancers and also serves as an independent predictor of death from some cancers. ${ }^{29-32}$ Thus, the risk factors of cancer have been transferred from pollution or infection to consumption of tobacco and alcohol, excessive nutrition and physical inactivity; the latter also promotes death related to diabetes- and cardio-cerebrovascular disease, possibly by inducing systemic inflammation..$^{33,34}$ The proportion of deaths related to cardio-cerebrovascular disease or cancer has continued to increase over the past 42 years. This trend is projected to continue in the future. Our projections of all-cause and cause-specific mortality provide an estimate of the future disease burden and are fundamental to the process of planning for disease control programs. This study can provide references for planning disease control and health promotion programs in other urban centres around the world. Socioeconomic events in the past should be taken into consideration when designing strategies for the prevention and control of diseases, especially noncommunicable diseases.

\section{Limitations}

As this is a descriptive study, it is difficult to confirm the causal association between socioeconomic events and cause-specific mortality. Although socioeconomic events usually affected the 
entire population under China's constitutional system, the extent of events such as famine in urban Shanghai could not be measured using indicators, resulting in a failure to quantify the associations. In addition, we did not stratify according to residents' socioeconomic states, limiting interpretation of our findings.

\section{Conclusion}

Birth cohorts exposed to the Great Chinese Famine in early life had increased mortality from several chronic diseases in later life. Decreased cause-specific mortality followed improvements in public health infrastructure and medical service as well as pollution control. For cancer and diabetes, however, benefits that might be attributable to these changes appear to have been overridden by exposure to new risk factors in a new generation. Cancer is a major cause of premature death. Cardio-cerebrovascular disease and cancer are set to continue to be the major disease burdens in the future.

\section{References}

1. GBD 2015 Mortality and Causes of Death Collaborators. Global, regional, and national life expectancy, all-cause mortality, and cause-specific mortality for 249 causes of death, 1980-2015: a systematic analysis for the Global Burden of Disease Study 2015. Lancet 2016;388:1459-544.

2. GBD 2016 Causes of Death Collaborators. Global, regional, and national age-sex specific mortality for 264 causes of death, 1980-2016: a systematic analysis for the Global Burden of Disease Study 2016. Lancet 2017;390:1151-210.

3. Zhou M, Wang H, Zhu J, et al. Cause-specific mortality for 240 causes in China during 1990-2013: systematic subnational analysis for the Global Burden of Disease Study 2013. Lancet 2016;387:251-72.

4. He C, Liu L, Chu Y, et al. National and subnational all-cause and cause-specific child mortality in China, 1996-2015: a systematic analysis with implications for the Sustainable Development Goals. Lancet Glob Health 2017;5: e186-97.

5. Sidebotham P, Fraser J, Fleming P, et al. Patterns of child death in England and Wales. Lancet 2014;384:904-14.

6. National data [in Chinese]. Beijing (China): National Bureau of Statistics of China; 2016. Available: http://data.stats.gov.cn/easyquery.htm?cn=C01 (accessed 2017 June 10).

7. Zou S-r, Shi A-z, Gao W-w, et al. The changing trends of the dietary patterns in Shanghai residents [article in Chinese]. Shanghai J Prev Med 2006;18:311-4.

8. Shanghai statistical yearbook [in Chinese]. Shanghai Shi (China): Shanghai Bureau of Statistics; 2016. Available: www.stats-sh.gov.cn/html/xxgk/gkml/ sjfw/.html (accessed 2017 July 1).

9. Wong T-C, Yeow M-C, Zhu X. Building a global city: negotiating the massive influx of floating population in Shanghai. J Hous Built Environ 2005;20:21-50.

10. Kim HJ, Fay MP, Feuer EJ, et al. Permutation tests for joinpoint regression with applications to cancer rates. Stat Med 2000;19:335-51.

11. Doll R, Cook P. Summarizing indices for comparison of cancer incidence data. Int J Cancer 1967;2:269-79.
12. Carstensen B. Age-period-cohort models for the Lexis diagram. Stat Med 2007;26:3018-45.

13. Wang JY, Hu SL, Liu HY, et al. Risk factor analysis of an epidemic of hepatitis A in a factory in Shanghai. Int J Epidemiol 1990;19:435-8.

14. GBD 2013 Mortality and Causes of Death Collaborators. Global, regional, and national age-sex specific all-cause and cause-specific mortality for 240 causes of death, 1990-2013: a systematic analysis for the Global Burden of Disease Study 2013. Lancet 2015;385:117-71.

15. Hansel NN, McCormack MC, Kim V. The effects of air pollution and temperature on COPD. COPD 2016;13:372-9.

16. Yang Z, Zhao W, Zhang X, et al. Impact of famine during pregnancy and infancy on health in adulthood. Obes Rev 2008;9(Suppl 1):95-9.

17. Zheng X, Wang Y, Ren W, et al. Risk of metabolic syndrome in adults exposed to the great Chinese famine during the fetal life and early childhood. Eur J Clin Nutr 2012;66:231-6.

18. Huang C, Li Z, Wang M, et al. Early life exposure to the 1959-1961 Chinese famine has long-term health consequences. J Nutr 2010;140:1874-8.

19. Li Y, He Y, Qi L, et al. Exposure to the Chinese famine in early life and the risk of hyperglycemia and type 2 diabetes in adulthood. Diabetes 2010;59:2400-6.

20. Chen JP, Peng B, Tang L, et al. Fetal and infant exposure to the Chinese famine increases the risk of fatty liver disease in Chongqing, China. J Gastroenterol Hepatol 2016;31:200-5.

21. St Clair D, Xu M, Wang P, et al. Rates of adult schizophrenia following prenatal exposure to the Chinese famine of 1959-1961. JAMA 2005;294:557-62.

22. Li QD, Li H, Li FJ, et al. Nutrition deficiency increases the risk of stomach cancer mortality. BMC Cancer 2012;12:315.

23. Li X, Li X, Lin H, et al. Metabolic syndrome and stroke: a meta-analysis of prospective cohort studies. J Clin Neurosci 2017;40:34-8.

24. Matthews LC, Hanley NA. The stress of starvation: glucocorticoid restraint of beta cell development. Diabetologia 2011;54:223-6.

25. Gu MJ, Huang QC, Bao CZ, et al. Attributable causes of colorectal cancer in China. BMC Cancer 2018;18:38.

26. Li M, Wang S, Han X, et al. Cancer mortality trends in an industrial district of Shanghai, China, from 1974 to 2014, and projections to 2029. Oncotarget 2017;8:92470-82.

27. Li Q, Hsia J, Yang G. Prevalence of smoking in China in 2010. N Engl J Med 2011;364:2469-70.

28. Chen ZM, Peto R, lona A, et al. Emerging tobacco-related cancer risks in China: a nationwide, prospective study of 0.5 million adults. Cancer $2015 ; 121$ (Suppl 17):3097-106.

29. Lv J, Yu C, Guo Y, et al.; China Kadoorie Biobank Collaborative Group. Adherence to a healthy lifestyle and the risk of type 2 diabetes in Chinese adults. Int J Epidemiol 2017;46:1410-20.

30. Coughlin SS, Calle EE, Teras LR, et al. Diabetes mellitus as a predictor of cancer mortality in a large cohort of US adults. Am J Epidemiol 2004;159:1160-7.

31. Shikata K, Ninomiya T, Kiyohara Y. Diabetes mellitus and cancer risk: review of the epidemiological evidence. Cancer Sci 2013;104:9-14.

32. Ben $\mathrm{Q}, \mathrm{Xu} \mathrm{M}, \mathrm{Ning} \mathrm{X}$, et al. Diabetes mellitus and risk of pancreatic cancer: a meta-analysis of cohort studies. Eur J Cancer 2011;47:1928-37.

33. Singh-Manoux A, Shipley MJ, Bell JA, et al. Association between inflammatory biomarkers and all-cause, cardiovascular and cancer-related mortality. CMAJ 2017;189:E384-90.

34. Hunt KJ, Jaffa MA, Garrett SM, et al. Plasma connective tissue growth factor (CTGF) CCN2) levels predict myocardial infarction in the Veterans Affairs Diabetes Trial (VADT) cohort. Diabetes Care 2018;41:840-6.

\section{Competing interests: None declared.}

This article has been peer reviewed.

Affiliations: Department of Epidemiology (Wang, Du, Yang, M. Li, Zhang, Liu, Song, Cao), Second Military Medical University; Department of Chronic Diseases (Han, Zhao, H. Li), Center for Disease Control and Prevention of Yangpu District, Shanghai, China

Contributors: Guangwen Cao and Xue Han contributed to the conception and design of the study. Xue Han, Jia Zhao, Hui Li, Hongwei Zhang, Fan Yang, Wenbin Liu, Mi Li and Jiahui Song contributed to the collection, interpre- tation and analysis of the data. Shuo Wang, Xiaoyu Du, Hongwei Zhang and Guangwen Cao contributed to the statistical analysis and interpretation of the analysis. Guangwen Cao drafted the manuscript. All authors revised the manuscript critically for important intellectual content, gave final approval of the version to be published and agreed to be accountable for all aspects of the work. Shuo Wang, Xiaoyu Du, and Xue Han contributed equally to this work.

Funding: This study was funded by the National Key Basic Research Program of China (No. 2015CB554000) and Three-Year Action Plan on
Public Health, Phase IV, Shanghai, China (No. 15GWZK0801). The funders had no role in the design and conduct of the study; collection, management, analysis or interpretation of the data; preparation, review or approval of the manuscript; and decision to submit the manuscript for publication.

Data sharing: Data are available upon reasonable request to the corresponding author.

Accepted: Aug. 9, 2018

Correspondence to: Guangwen Cao, gcao@smmu.edu.cn 